\title{
An alternative treatment option in the atrophied maxilla without sinus lift and bone graft-A case report
}

\author{
Jimoh Olubanwo Agbaje ${ }^{1}$, Mohamed Ahariz ${ }^{2}$ and Henri Diederich ${ }^{2 *}$ \\ ${ }^{1}$ UCLL Hogeschool, Campus Gasthuisberg, Herestraat 49, 3000 Leuven, Belgium \\ ${ }^{2}$ Dental Clinic Henri Diederich, 114 av. de la Faiencerie, L-1511, Luxembourg
}

\begin{abstract}
Severely atrophied jaws and extremely resorbed alveolar bone with insufficient height (10mm) and width (6mm) for conventional implant placement present limitations for implant rehabilitation of edentulous jaws.

In some cases, there may be a need for extensive invasive procedures, which patients may not want to undergo either due to morbidity risks, economic reasons or other undisclosed genuine reasons.

Various anatomical reasons limit the use of conventional intraosseous implants in restoring some edentulous spaces.

The Cortically Fixed at Once approach implant systems were recently introduced to improve management of various edentulous cases and to give patients wide treatment options where conventional implant has failed.

The case report below describes steps followed for the functional restoration of an edentulous patient with the CF@O implant system without bone grafts or sinus lift.
\end{abstract}

\section{Introduction}

That a severely atrophied maxilla usually presents limitations for conventional implant placement has been shown in the literature so also are the limitations of conventional implant to restore some edentulous spaces due to various anatomical reason [1-7].

Extremely resorbed alveolar bone with insufficient height $(10 \mathrm{~mm})$ and width $(6 \mathrm{~mm})$ for conventional implant placement, the insufficient space between adjacent edentulous teeth for the use of conventional implant, or the presence of neurovascular bundles that may make implant placement impossible are but to mentioned few of these reasons $[2,3,6,7]$.

In some cases there may be a need for extensive invasive procedures, such as free or microvascular bone grafts, onlay grafts, transport distraction osteogenesis, apposition grafts with or without a Le Fort I osteotomy to enable placement of a sufficient number and length of implants [8-12].

In some cases, patients do not want to undergo these further operations either due to morbidity risks, economic reasons or other undisclosed genuine reasons. In these situations, an alternative implant system is required.

In the recent past, many new implant systems were introduced to improve management of various edentulous cases and to give patients wide treatment options.

One of such implant systems is the Cortically Fixed at Once approach (CF@O) [13]. The CF@O system incorporates ranges of treatment options for management of edentulism, and it is an alternative to extensive surgical procedures in situations where there is substantial bone resorption [14-17]. The CF@O Implant system consists of several types of components specifically developed for different locations in the jaws [18].

$\mathrm{CF} @ \mathrm{O}$ uses the concept of tricortical support anchorage where the available residual bone volume is used for support $[14,18]$. The challenges of a severely atrophied jaw due to advanced posterior alveolar resorption combined with increased maxillary sinus pneumatization which often leaves insufficient bone for implant anchorage can easily be managed [19].

The implant system incorporates the whole range of treatment procedures and it encourages early loading. It ensures that patient edentulism can be taken care of immediately with the restoration of function and aesthetics within a few days [17].

\section{Case presentation}

A 65-year-old non-smoker male patient in good health came to our clinic, he wanted fixed teeth in the maxilla. From previous consultations in the other centres, various treatment options such as sinus lifts or bone graft were proposed due to the severe jaw atrophy. The patient was afraid of these suggested procedures, he said he preferred an implants treatment that can accommodate his present bone conditions.

A clinical examination showed an edentulous upper arch with a severely resorbed ridge. In the lower jaw, several teeth were present in the frontal region and in the right and the left lateral regions.

${ }^{*}$ Correspondence to: Henri Diederich, Dental surgeon, Dental Clinic Henri Diederich, 114 av. de la Faiencerie, L- 1511 Luxembourg, Tel: +352621144664; E-mail: hdidi@pt.lu

Received: March 01, 2020; Accepted: March 16, 2020; Published: March 19, 2020 
Figure 1 shows the panoramic radiograph of the patient at presentation. Radiographic examination using an orthopantomogram showed an edentulous upper jaw with moderate vertical bone resorption in the front and severe vertical resorption in the premolar and molar region.

In the lower jaw, several teeth were present in the frontal region and in the right lateral region. Most of the teeth show a moderate to severe bone loss suggestive of chronic periodontitis.

After the clinical examination and the study of patient's orthopantomogram, surgical planning was formulated. Usually 2-piece implants anchored to cortical bone, such as the Pterygoid bone would have been used, but in order to overcome the problem of severe bone atrophy, it may be better to choose implants that are adaptable to the bone such as Hybrid Plates.

From a prosthetic point of view, the patient desired a fixed prosthetic solution, so the following treatment plan was suggested: In the upper jaw, a combination of two pterygoids, five one-piece implants and two hybrid plates were proposed. The patient agreed to this.

Surgery was performed under local anaesthesia.

The local anaesthesia was injected in the left and right maxillary vestibule and in the palate. An open flap was made from the left tuberosity along the crest ending in the front behind region 13 in the maxilla. The flap was reflected on the vestibular side in positions 26 and 27 of the zygomatic arch; the flap was also reflected in the palate. A Pterygoid implant C35/20mm (ROOTT - implant Trate AG) was gently inserted at position 28 with a $50 \mathrm{~N}$ torque. One Hybrid Plate HENGG-1 (Highly Efficient No Graft Gear) was adapted to the bone anatomy in position 26 . A bed was prepared to receive the plate and promote osseointegration of the plate. The highly flexible plate is adapted perfectly to the bone and fixed with osteosynthesis screws.

Root form implants with a high primary stability were inserted in the frontal region (three on the right maxillary bone and two on the left maxillary bone).

The procedure was quite similar for the right side. A plate HENGG-1 was installed in position 16 and one Pterygoid implant $\mathrm{P} 35 / 20 \mathrm{~mm}$ was inserted at the right pterygoid plate (Figure 2).

The hybrid plates were fixed with osteosynthesis screws and covered with an antibiotic Metronidazole (to prevent risk of contamination) and bone material Curasan ${ }^{\mathrm{R}}$.

The procedure was quite similar for the right side. A plate HENGG-1 was installed in position 16 and one Pterygoid implant P35/20mm was inserted at the right pterygoid plate Figure 3.

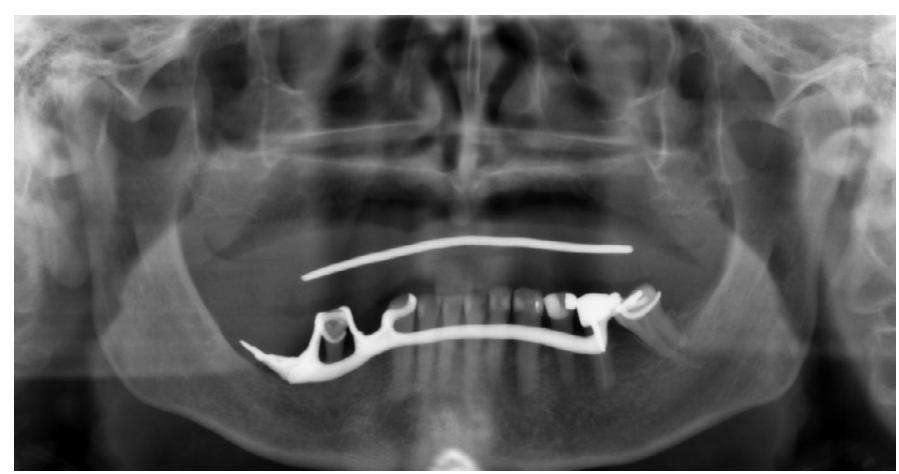

Figure 1. Panoramic radiograph of the patient at presentation

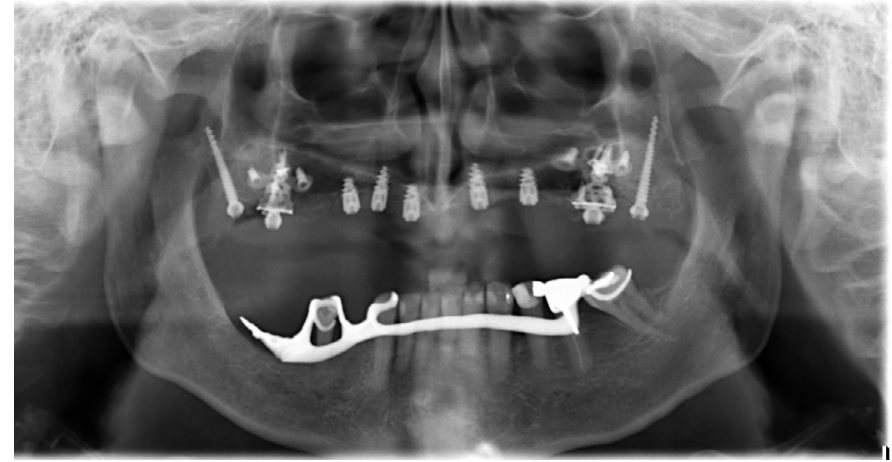

Figure 2. Panoramic radiograph of the patient after implant placement
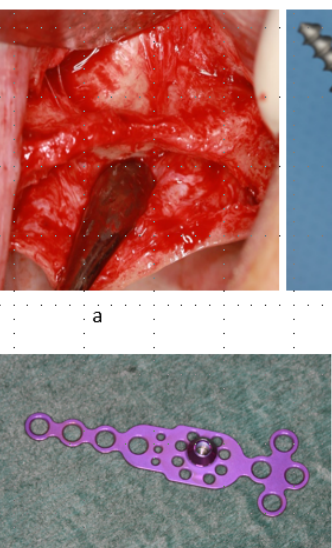
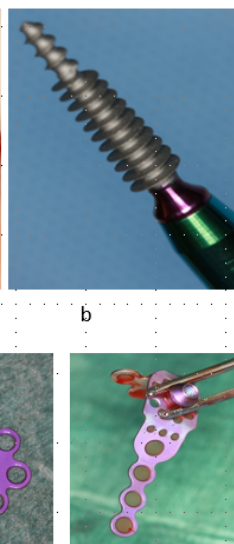
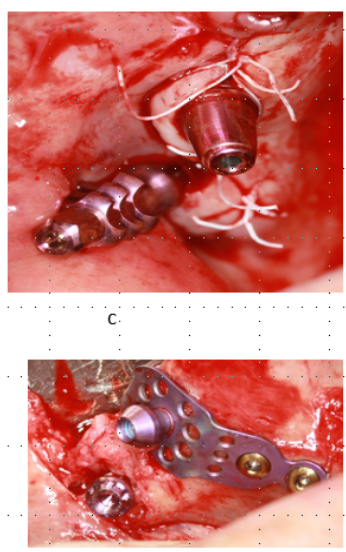

Figure 3. Surgical procedure and implant placement $(a-f)$

The plate was fixed with osteosynthesis screws and covered with an antibiotic Metronidazole and bone material Curasan ${ }^{\mathrm{R}}$ (repetition)

The flap was then closed on the right and left with polytetrafluoroethylene polymer (PTFE) monofilament absorbable suture. Patient was placed on antibiotics (amoxycilline $2 \mathrm{~g}$ per day for 10 days) immediately after surgery and an injection of corticosteroid (Diprophos) in the muscle in order to prevent pain and swelling.

The patient was wearing full prosthesis which was used for bite registration. Due to severe jaw atrophy loading was delayed and patient was instructed to wear his prothesis only when needed. After 2 weeks stiches were removed. 3 months later the cover screws were removed and healing caps were placed.

The impression was done with screwed transfers and in the following session a key in resin duralay ${ }^{\mathrm{R}}$ was tried in to check the impression. There after a plater key was delivered by the laboratory to check the passivity, which was perfect.

The frame work was tried in and a metal acrylic bridge was chosen for economic reasons. A first try in with the future bridges was done, aesthetics and bite were also controlled. On the following appointment the try-in and prosthesis delivery was done. The metal acrylic bridge was screwed and cemented in the front of the maxilla. (Figures 4 and 5). The patient was reviewed after 2 weeks. Thereafter, patient was scheduled for follow-up at 3 months and then every 6 months. There were no reported complications throughout the treatment. 

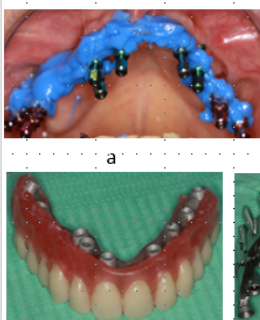

e

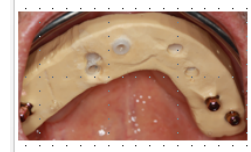

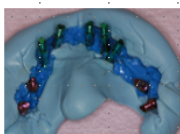

b.

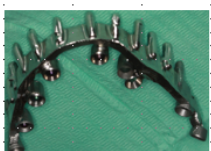

f

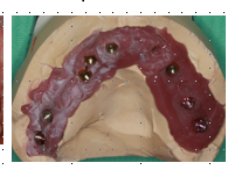

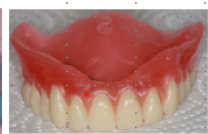

c.

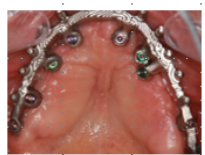

g

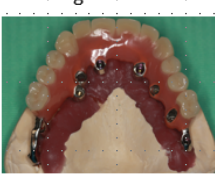

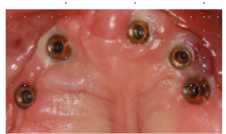

d
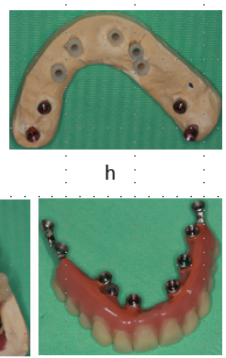

Figure 4. Laboratory steps- Bite registration, impression taken procedure, plater key and bridge fabrication
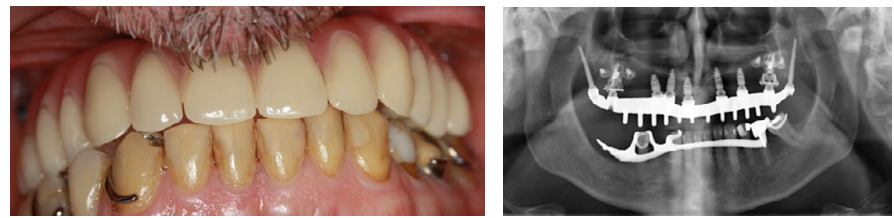

Figure 5. Clinical photograph and the panoramic radiograph of patient after bridge delivery

\section{Discussion}

The presented case report describes how CF@O implant system was used for the functional restoration of an edentulous patient with atrophied jaw who does not want additional surgical procedure such as sinus lift and bone grafts. With the CF@O implant system the patient problem of edentulism in the upper jaw could be solved without additional surgical procedures.

Rehabilitation of such difficult cases is achieved within a short period of time and the patient need was met without additional surgical operation. In the above case reports, CF@O hybrid plate root form implants and pterygoid implants were used for patient rehabilitation.

The CF@O, Cortically Fixed at Once approach has been shown to be a reliable alternative to bone grafts and sinus lift in situations where there is a substantial bone resorption.

\section{Conflicts of interest}

There are no conflicts of interest to be disclosed.

\section{References}

1. Ali SA, Karthigeyan S, Deivanai M, Kumar A (2014) Implant rehabilitation for atrophic maxilla: a review. J Indian Prosthodont Soc 14: 196-207. [Crossref]

2. Bosse LP, Taylor TD (1998) Problems associated with implant rehabilitation of the edentulous maxilla. Dent Clin North Am 42: 117-127. [Crossref]

3. Candel E, Penarrocha D, Penarrocha M (2012) Rehabilitation of the atrophic posterior maxilla with pterygoid implants: a review. J Oral Implantol 38: 461-466. [Crossref]

4. Jivraj S1, Chee W, Corrado P (2006) Treatment planning of the edentulous maxilla. $B r$ Dent J 201: 261-279. [crossref]

5. Sevetz EB Jr (2006) Treatment of the severely atrophic fully edentulous maxilla: the zygoma implant option. Atlas Oral Maxillofac Surg Clin North Am 14: 121-136. [Crossref]

6. Candel-Marti E, Carrillo-Garcia C, Penarrocha-Oltra D, Penarrocha-Diago M (2012) Rehabilitation of atrophic posterior maxilla with zygomatic implants: review. J Oral Implantol 38: 653-657. [Crossref]

7. Mericske-Stern RD1, Taylor TD, Belser U (2000) Management of the edentulous patient. Clin Oral Implants Res 11 Suppl 1: 108-125. [crossref]

8. Yaremchuk MJ1 (1989) Vascularized bone grafts for maxillofacial reconstruction. Clin Plast Surg 16: 29-39. [crossref]

9. Sjostrom M, Sennerby L, Nilson H, Lundgren S (2007) Reconstruction of the atrophic edentulous maxilla with free iliac crest grafts and implants: a 3-year report of a prospective clinical study. Clin Implant Dent Relat Res 9: 46-59. [Crossref]

10. Cheung LK, Zhang Q, Zhang ZG, Wong MC (2003) Reconstruction of maxillectomy defect by transport distraction osteogenesis. Int J Oral Maxillofac Surg 32: 515-522. [Crossref]

11. Nyström E, Nilson H, Gunne J, Lundgren S (2009) Reconstruction of the atrophic maxilla with interpositional bone grafting/Le Fort I osteotomy and endosteal implants a 11-16 year follow-up. Int J Oral Maxillofac Surg 38: 1-6. [crossref]

12. Ugurlu F, Yildiz C, Sener BC, Sertgoz A (2013) Rehabilitation of posterior maxilla with zygomatic and dental implant after tumor resection: a case report. Case Rep Dent 2013: 930345. [Crossref]

13. Agbaje JO, Diederich H (2019) Cortically Fixed at Once Implants for the Treatment of the Atrophic Maxilla - A Case Report. Adv Dent \& Oral Health 1: 001-005.

14. Agbaje JO, Meeus J, Vrielinc L, Diederich H (2018) Rehabilitation of Atrophic Maxilla using Pterygoid Implants: Case Reports. Modern Approaches in Dentistry and Oral Health Care 1: 1-6.

15. Agbaje JO, Diederich H (2018) Minimal Invasive Modality for Full Rehabilitation of Edentulous Mandible with One-Piece Implants in Elderly Patients; A Case Report. $A d v$ Dent \& Oral Health 8: 001-006.

16. Agbaje JO, Diederich H (2018) Minimal Invasive Concept for the Rehabilitation of Edentulous Jaw with One-piece Implants. International Journal of Case Reports \& Short Reviews 4: 028-030.

17. Henri Diederich, Alexandre Junqueira Marques, and LÃ Co GuimarÃ£es Soares. Immediate Loading of an Atrophied Maxilla Using the Principles of Cortically Fixed Titanium Hybrid Plates. Advances in Dentistry \& Oral Health (ADOH) 3: 001-003.

18. Agbaje JO, Diederich H (2018) Use of cortically fixed at once implants for the treatment of atrophic and extreme athrophic jaws. Africa journal of Dentistry and Implantology 43-50.

19. Penarrocha-Oltra D, Candel-Marti E, Ata-Ali J, Penarrocha-Diago M (2013) Rehabilitation of the atrophic maxilla with tilted implants: review of the literature. $J$ Oral Implantol 39: 625-632. [Crossref]

Copyright: (C2020 Agbaje JO. This is an open-access article distributed under the terms of the Creative Commons Attribution License, which permits unrestricted use, distribution, and reproduction in any medium, provided the original author and source are credited. 